\title{
Web-Based Bag And Luggage Sales Information System At Cv. Purnama
}

\section{Sistem Informasi Penjualan Tas Dan Koper Berbasis Web Pada Cv. Purnama}

\author{
Farid Musyafa' ${ }^{1}$, Sumarno ${ }^{2}$ \\ \{ faridmusyafa13@gmail.com ${ }^{1}$, sumarno@umsida.ac.id ${ }^{2}$ \}
}

Program Studi Informatika, Universitas Muhammadiyah Sidoarjo, Indonesia ${ }^{1,2}$

\begin{abstract}
This study aims to design and create a web-based information system that functions to help manage the sales process at CV. Purnama. This research was conducted in March 2020 at the Informatics Laboratory, University of Muhammadiyah Sidoarjo and CV. Purnama. This research was conducted using the waterfall method, data were collected through interviews, literature study, and problem analysis. The results of this study are in the form of WebBased Bag and Suitcase Sales Information Systems at CV. Purnama which aims to increase promotion and facilitate the operational management in CV. Purnama. This information system has two actors, namely admin as manager of information systems and customers as consumers. Based on this research, the conclusion is that with the sales system (e-commerce), CV. Purnama can facilitate the conventional transaction process to become more modern with the availability of online transactions.
\end{abstract}

Keywords - Information Systems; Bag Sales; Web

\begin{abstract}
Abstrak. Penelitian ini bertujuan untuk merancang dan membuat sistem informasi berbasis web yang berfungsi untuk membantu mengelola proses penjualan pada CV. Purnama. Penelitian ini dilaksanakan pada bulan maret tahun 2020 di Laboratoriuam Informatika Universitas Muhammadiyah Sidoarjo dan CV. Purnama. Penilitian ini dilakukan dengan metode waterfall, data dikumpulkan melalui wawancara, studi kepustakaan, dan analisa permasalahan. Hasil dari Penelitian ini yaitu berupa Sistem Informasi Penjualan Tas dan Koper Berbasis Web Pada CV. Purnama yang bertujuan untuk meningkatkan promosi dan mempermudah pengelolaan operasional yang ada di CV. Purnama. Sistem Informasi ini memiliki dua aktor yaitu admin sebagai pengelola sistem informasi dan pelanggan sebagai konsumen. Berdasarkan penelitian tersebut didapatkan kesimpulan bahwa dengan adanya sistem penjualan (ecommerce) maka CV. Purnama dapat memudahkan proses transaksi yang selama ini sifatnya konvensional menjadi lebih modern dengan tersedianya transaksi online.
\end{abstract}

Kata Kunci - Sistem Informasi; Penjualan Tas; Berbasis Web

\section{Pendahuluan}

\section{A. Latar Belakang}

Usaha Kecil Menengah (UKM) merupakan salah satu potensi usaha yang dapat meningkatkan kesejahteraan disetiap daerah. Salah satu unggulan UKM yang cukup menarik untuk disoroti yaitu pada Senta Industri Tas dan Koper Tanggulangin. Tanggulangin adalah salah satu kecamatan di Kabupaten Sidoarjo yang sebagian besar penduduknya bermata pencarian sebagai pengrajin tas dan koper yang nantinya akan dijual di dalam maupun luar kota. Beberapa desa yang mayoritas penduduknya bekerja sebagai pengrajin tas antara lain yaitu Desa Kludan dan Desa Kedensari. Karena sebagian penduduknya bekerja sebagai pengrajin tas, maka persaingan antar pengrajin pun tidak dapat dihindari. Oleh karena itu diperlukan strategi pemasaran yang efektif dan kreatif guna meningkatkan hasil penjualan. Salah satu cara yang dapat digunakan untuk meningkatkan hasil penjualan adalah dengan meningkatkan upaya strategi pemasaran produk hasil usaha dengan mengaplikasikan metode pemasaran melalui sistem informasi penjualan. Menurut penelitian yang dilakukan oleh Nandang Iriadi dan Ade Ustami dalam jurnalnya "Sistem Informasi Penjualan Berbasis Web Pada CV. Bambu Jaya Jakarta" menyatakan bahwa sistem penjualan yang telah terkomputerisasi secara online dan memberikan keluaran (output) yang berguna bagi customer sebagai bukti transaksi[1]. Selain itu pengolahan data penjualan yang diinputkan oleh admin menghasilkan suatu penyimpanan data secara digital karena tersimpan dalam database menurut file-nya masing-masing. Dalam dunia bisnis, media website penjualan sudah merupakan kebutuhan dari suatu bisnis yang telah maju saat ini untuk pengembangan suatu usaha dikarenakan akan didapatkan berbagai manfaat dari media tersebut.

CV. Purnama adalah salah satu badan usaha yang bergerak dalam bidang penjualan tas dan koper. Pengrajin tas pada CV. Purnama mempunyai skill yang baik sehingga tas dan koper yang dihasilkan pun berkualitas. Hasil produksi CV. Purnama nantinya akan dijual baik di dalam maupun luar kota, baik secara offline maupun online. Berdasarkan observasi yang dilakukan peneliti pada CV. Purnama dengan metode pengamatan, didapatkan hasil bahwa di CV. Purnama sampai saat ini sistem informasinya masih dalam bentuk konvensional. 
Pada perusahaan tersebut, admin masih merekap data penjualan secara manual dengan menggunakan buku. Sistem informasi yang konvensional seperti ini akan menyebabkan ketidak-efektifan dalam operasionalnya, misalnya saja terjadinya kesalahan saat merekap data jual beli. Menurut Ferdika dan Kuswara menyatakan bahwa dengan sistem informasi berbasis web maka semua pengolahan data dilakukan secara komputerisasi yang dilakukan oleh sistem sehingga dapat memperkecil kesalahan dan lebih aman[2]. Pemesanan produk pada sistem informasi berbasis website ini juga menghemat waktu dan biaya dibandingkan dengan pemesanan secara langsung datang ke lokasi. Oleh karena itu dalam penelitian ini, penulis akan membuat sistem informasi berbasis web untuk penjualan tas dan koper agar lebih memudahkan dalam proses pengolahan data.

Berdasarkan uraian tersebut, maka penulis memiliki ide untuk membuat Sistem Informasi Penjualan Tas dan Koper Berbasis WEB Pada CV. Purnama. Sistem informasi ini memiliki dua aktor, yaitu admin dan pembeli. Admin dapat melakukan update stok barang dan konfirmasi pembayaran. Sedangkan pembeli dapat melakukan pemesanan barang, melakukan pembayaran melalui transfer via rekening kemudian di konfirmasi kepada admin.

\section{B. Kajian Literatur Terdahulu}

\begin{tabular}{llllll}
\hline \multicolumn{2}{c}{ Nama } & Tahun & \multicolumn{1}{c}{ Judul } & \multicolumn{1}{c}{ Hasil } \\
\hline Fabriyan Fandi & Dwi & 2017 & Sistem Informasi Penjualan & Sistem informasi yang mempermudah \\
Imanawati dan & Umi & & Sepatu Berbasis Web Pada Vegas & penjualan sepatu pada toko Vegas Hyper \\
Maelani Elsa & & & Hyper Purwokerto[3] & Purwokerto
\end{tabular}

Dede Barkah dan Sri 2018 Wasiyanti
Sistem Informasi Penjualan Baju Berbasis Web Pada Project Distro $\operatorname{Depok}[4]$
Sistem informasi yang mempermudah penjualan baju pada Project Distro Depok

Dari beberapa sumber referensi tersebut memiliki persamaan latar belakang dengan penelitian yang dilakukan yaitu sama-sama membuat sistem informasi untuk pengoptimalan penjualan produk. Pada penelitian pertama dan kedua, sistem informasi dibuat dengan menggunakan metode waterfall.

\section{Tujuan Kajian Artikel}

Tujuan dari penelitian ini adalah untuk merancang dan membuat sistem informasi berbasis web yang berfungsi untuk membantu mengelola proses penjualan pada CV. Purnama.

\section{METODE}

\section{A. Alat Penelitian}

Dalam proses penelitian ini terdapat alat yang digunakan dalam menunjang penulis. Alat tersebut dijelaskan sebagai berikut :

1. Perangkat keras (hardware) yang seperangkat komputer dengan spesifikasi :
a. Prosesor : Intel Core i3 M380
b. RAM : $4 \mathrm{~GB}$
c. Harddisk : $500 \mathrm{~GB}$
d. Printer Epson L210

2. Perangkat lunak (software) yang digunakan sebagai berikut :
a. Sistem Operasi Windows 7 Ultimate 64-bit
b. PHP sebagai bahasa pemrograman
c. Xampp sebagai server
d. Notepad++ sebagai text editor
e. Mozila Firefox Developer Edition sebagai browser

\section{B. Bahan Penelitian}

Dalam penulisan penelitian ini, penulis melakukan penelitian pada CV. Purnama. Bahan penelitian yang digunakan dalam melakukan penelitian meliputi data-data yang menunjang dalam pembuatan sistem informasi penjualan tas dan koper.

1. Data Primer

Data primer adalah data yang dikumpulkan melalui pihak pertama, biasanya didapat melalui wawancara, jejak dan lain-lain [5]. Data tersebut didapat melalui wawancara kepada admin CV. Purnama serta data yang digunakan meliputi sejarah, profil CV. Purnama, produksi produk dan lain sebagainya

2. Data Sekunder 
Data sekunder adalah sumber data yang diperoleh dengan cara membaca, mempelajari dan memahami melalui media lain yang bersumber dari literatur, buku-buku, serta dikumen [6]. Data-data tersebut berasal dari berbagai sumber dan digunakan untuk mendukung informasi penelitian / penelitian yang dibutuhkan, yang menjadi dasar untuk memahami objek penelitian dan analisisnya yang benar. Selain itu, datanya berasal dari penelitian pustaka. penelitian kepustakaan sebagai kegiatan yang dilakukan secara sistematis untuk mengumpulkan, mengolah, dan menyimpulkan data dengan menggunakan metode / teknik tertentu guna mencari jawaban atas permasalahan yang dihadapi melalui penelitian kepustakaan [7].

\section{Teknik Pengumpulan Data}

Adapun metode pengumpulan data dan informasi yang digunakan dalam penelitian ini adalah:

1. Wawancara

Merupakan metode pengumpulan data yang digunakan dengan cara melakukan tanya jawab dengan pihak yang terkait dengan penelitian ini yaitu admin CV. Purnama mengenai masalah yang ada.

2. Studi Kepustakaan

Pengumpulan data dengan cara membaca jurnal, buku, artikel, maupun penelitian-penelitian terdahulu yang berhubungan dengan masalah yang diangkat penulis, untuk menunjang teori-teori dan landasan teori didalam penelitian.

3. Analisa Permasalahan

Mengkaji masalah yang ada pada CV. Purnama untuk penelitian lalu melakukan analisa masalah tersebut. Menganalisa permasalahan ini dilakukan untuk mengidentifikasi pokok permasalahan dan untuk menentukan batasan-batasan masalah [8].

\section{Metode Waterfall}

Metode yang digunakan pada pengembangan perangkat lunak yaitu metode waterfall, menurut Sukamto dan Shalahuddin terbagi menjadi lima tahapan, yaitu sebagai berikut :

1. Analisis kebutuhan perangkat lunak

Pada tahap ini akan dilakukan analisis mendalam terhadap perangkat lunak untuk memahami perangkat lunak yang dibutuhkan oleh pengguna, yaitu dengan mendesain tampilan situs web CV. Purnama (termasuk pendaftaran keanggotaan, produk yang tersedia, harga produk, pesanan dan pengiriman) dikelola oleh seorang admin yang memiliki hak akses.

2. Desain

Tahap ini mentransfer kebutuhan perangkat lunak dari tahap analisis kebutuhan ke tampilan desain sehingga dapat diimplementasikan ke dalam program. Langkah ini membutuhkan diagram alir data (DFD), relasi tabel dan perancangan antarmuka untuk memudahkan pembuatan website CV. Purnama.

3. Pembuatan kode program

Tahap selanjutnya adalah mengubah desain yang sudah buat menjadi program atau bahasa komputer yang disebut dengan coding. Penelitian ini menggunakan bahasa pemrograman seperti HTML, MySQL, PHP, CSS dan Javascipt.

4. Pengujian

Setelah website dibuat, maka akan dilakukan pengujian dengan menggunakan pengujian black box untuk meminimalkan kesalahan dan memastikan bahwa website yang dibuat sudah sesuai kebutuhan.

5. Pendukung (support) atau pemeliharaan (maintenance)

Pada beberapa kasus tidak menutup kemungkinan bahwa perangkat lunak dapat diubah setelah dikirim ke pengguna. Kemungkinan perubahan tidak terideteksi karena kesalahan yang terjadi selama proses pengujian atau perangkat lunak harus beradaptasi dengan kondisi baru [9][10].

\section{E. Konteks Diagram}

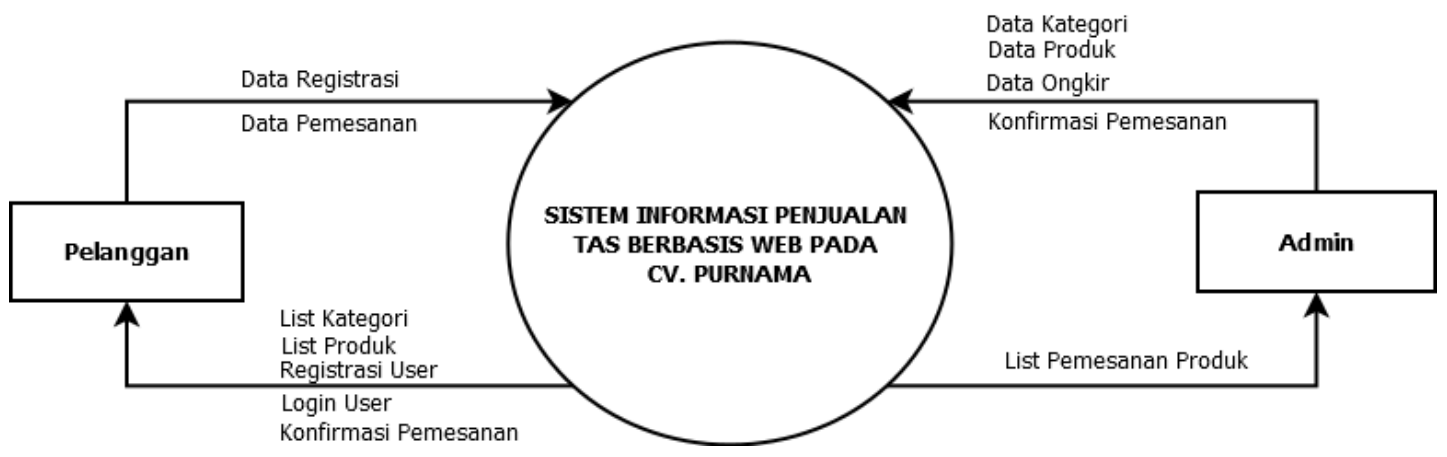

Gambar 2.1 Konteks Diagram 
Procedia of Engineering and Life Science Vol. 1. No. 2 Juni 2021

Seminar Nasional \& Call Paper Fakultas Sains dan Teknologi (SENASAINS 2nd)

Universitas Muhammadiyah Sidoarjo

\section{F. Data Flow Diagram}

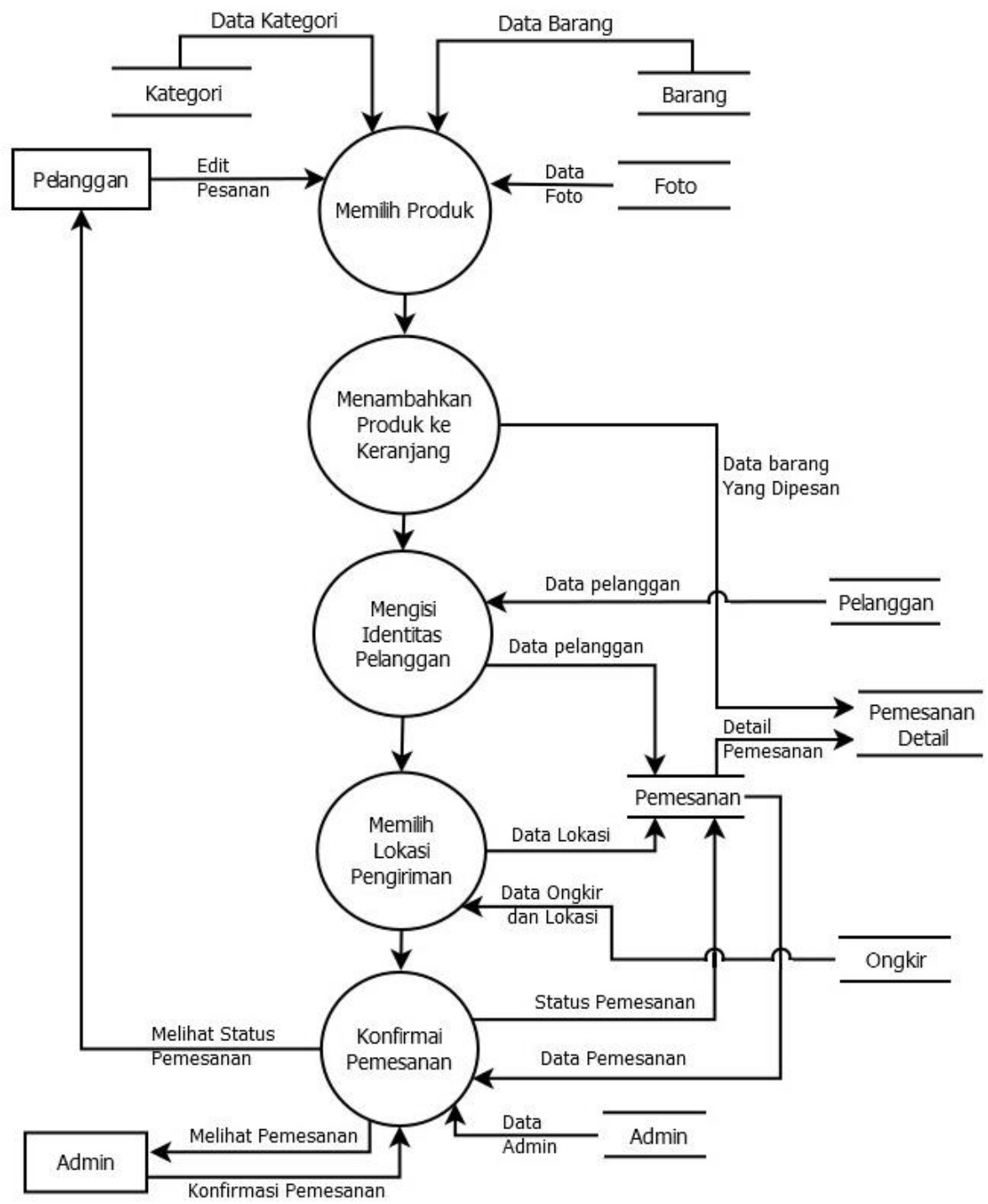

Gambar 2.2 DFD 
Procedia of Engineering and Life Science Vol. 1. No. 2 Juni 2021

Seminar Nasional \& Call Paper Fakultas Sains dan Teknologi (SENASAINS 2nd)

Universitas Muhammadiyah Sidoarjo

\section{G. Relasi Tabel}

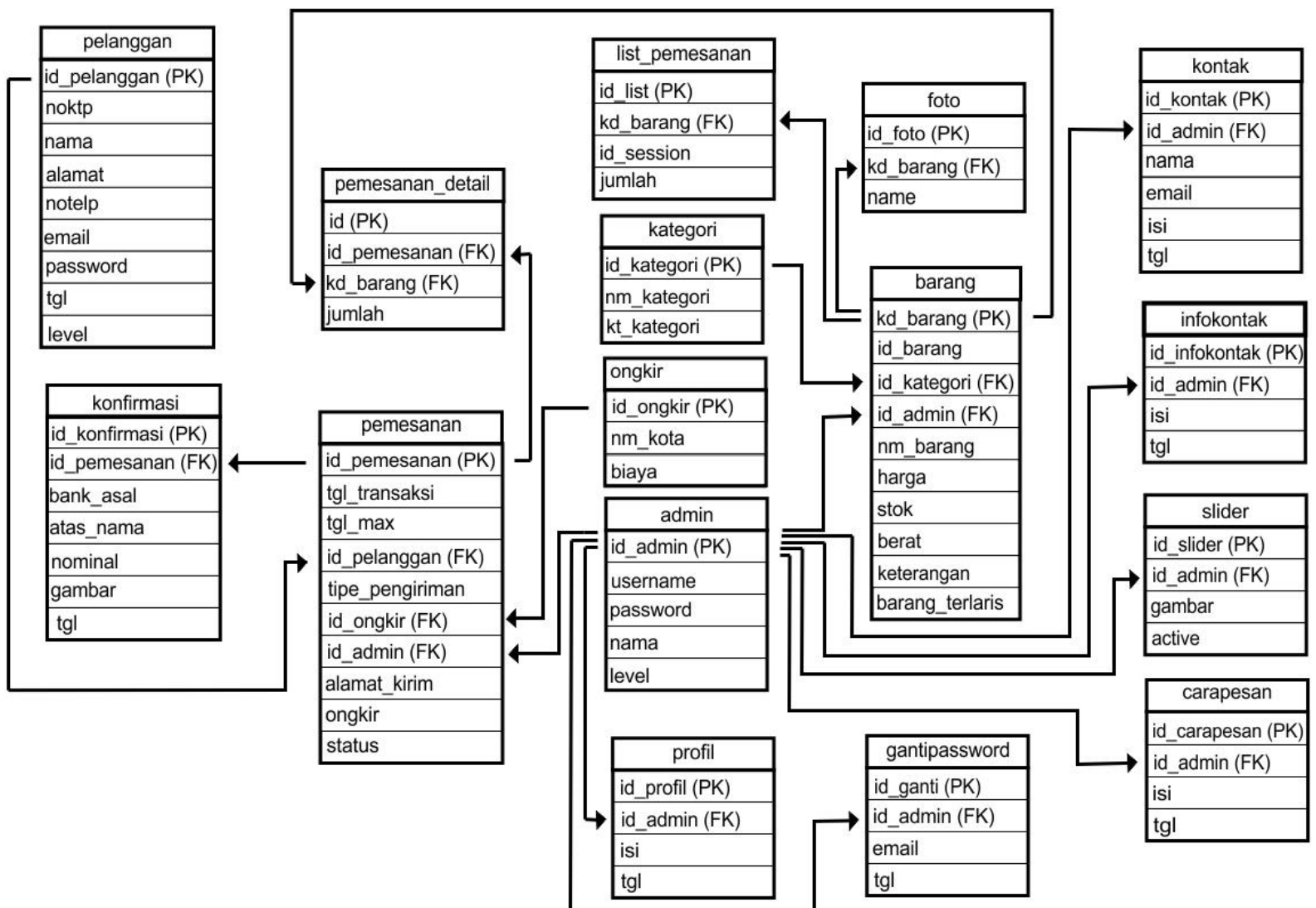

Gambar 2.3 Relasi Tabel

\section{HaSil dan Pembahasan}

\section{A. Hasil Penelitian}

Hasil Penelitian ini adalah perancangan dan pembuatan Sistem Informasi Penjualan Tas dan Koper Berbasis Web Pada CV. Purnama yang bertujuan untuk meningkatkan promosi dan mempermudah pengelolaan operasional yang ada di CV. Purnama. Sistem Informasi ini memiliki dua aktor yaitu admin sebagai pengelola sistem informasi dan pelanggan sebagai konsumen.

\section{B. Pembahasan Sistem}

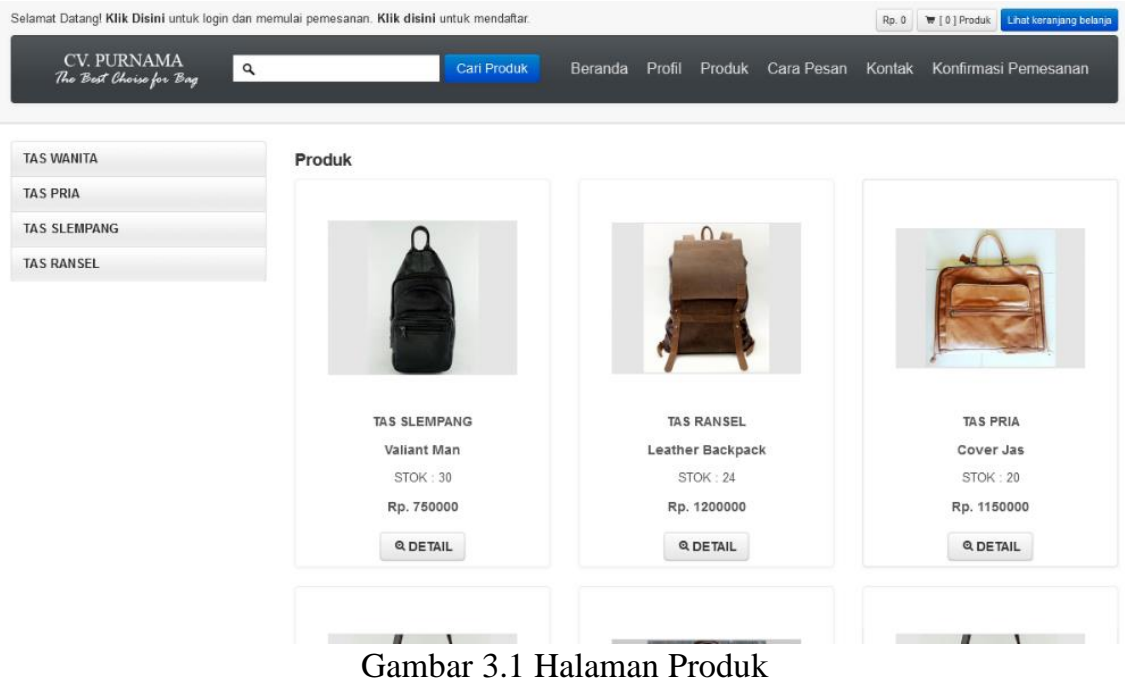


Halaman Produk adalah halaman yang menampilkan produk yang dijual di CV. Purnama dihalaman ini juga menampilkan informasi foto produk, nama produk, stok yang tersedia dan harga produk. Bebarapa tab menu antara lain, Menu profil menampilkan sekilas profil dari CV. Purnama. Menu Produk menampilkan produk. Menu cara pesan menampilkan informasi tata cara pesan. Menu kontak menampilkan informasi detail kontak, jam buka dan kritik saran pelanggan kepada CV. Purnama. Menu konfirmasi pemesanan menampilkan data pemesanan apabila ingin konfirmasi terdapat form konfirmasi dengan mengupload bukti transfer.

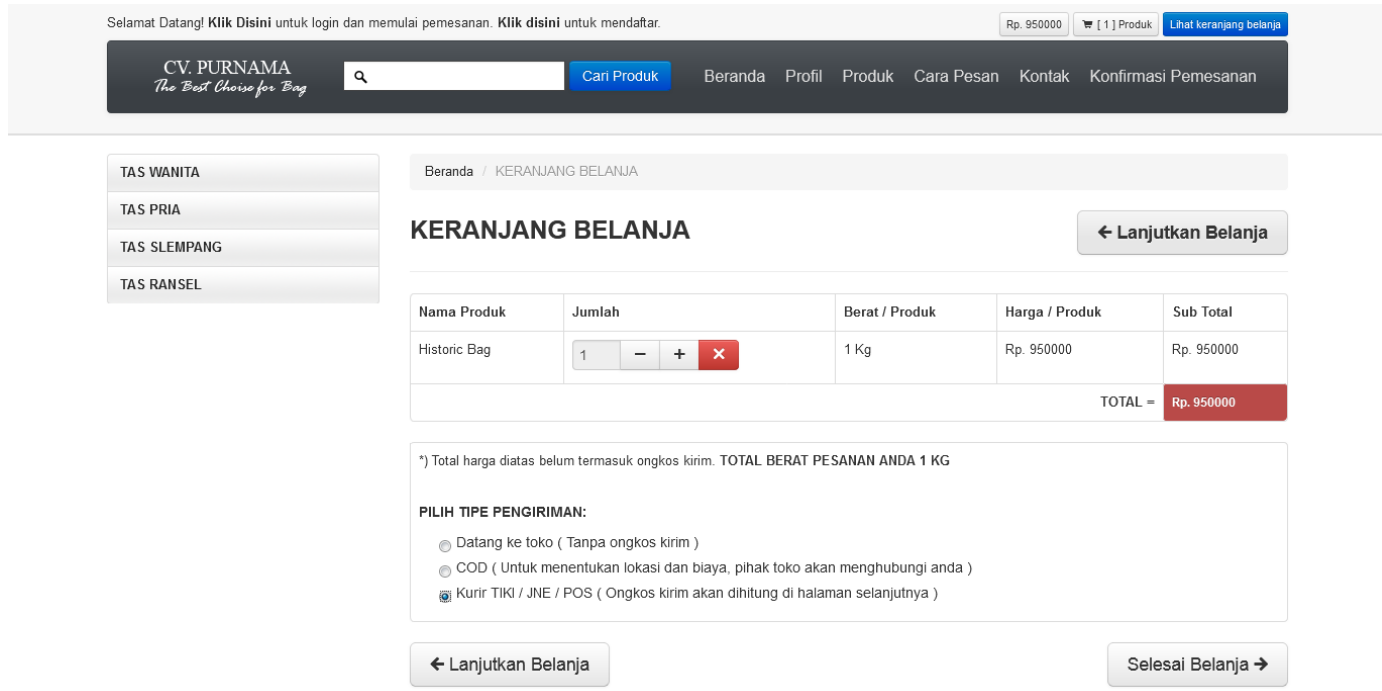

Gambar 3.2 Halaman Keranjang Belanja

Halaman Keranjang Belanja adalah halaman yang berisi list produk bisa beberapa produk sesuai yang ingin ditambahkan dan total biaya yang harus dibayar oleh pelanggan kemudian pilih tipe pengiriman kemudian untuk melanjutkan pemesanan pelanggan harus memilih selesai belanja.

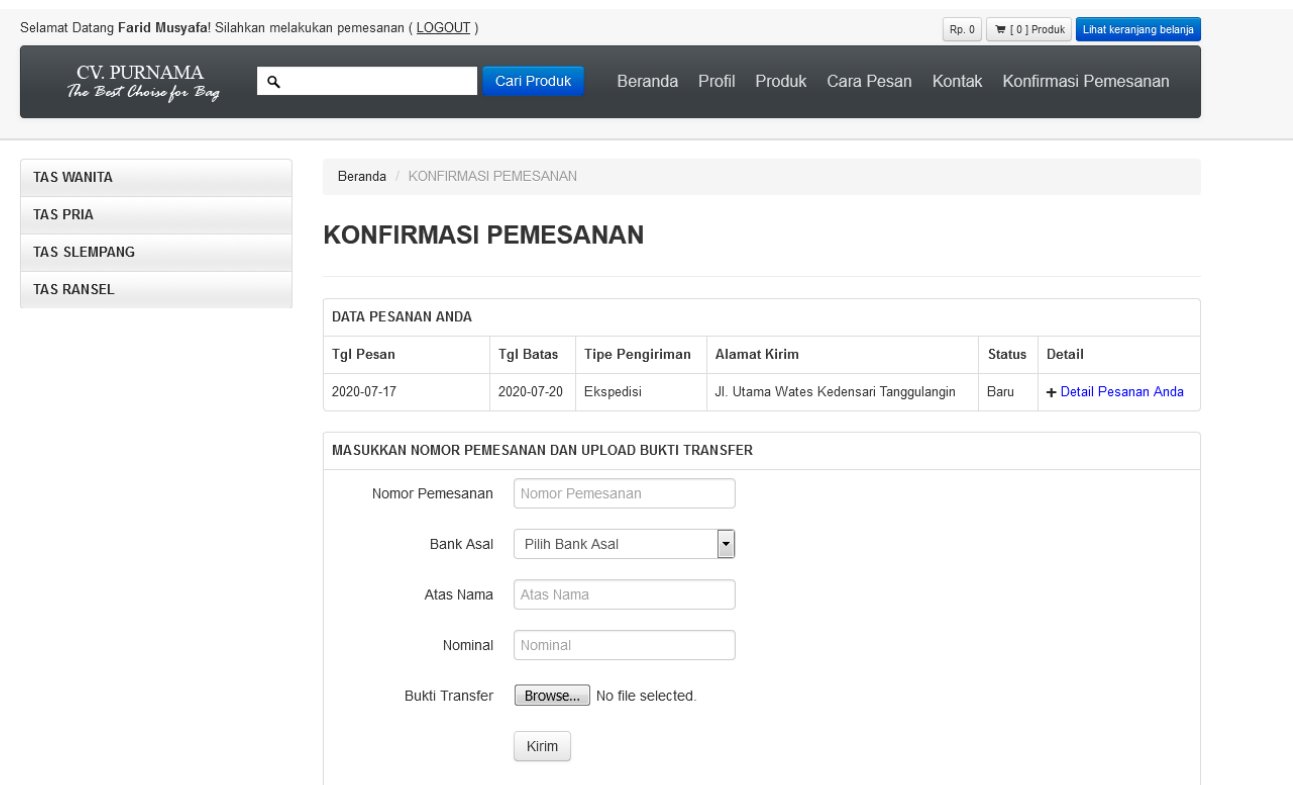

Gambar 3.3 Halaman Konfirmasi Pemesanan

Halaman Konfirmasi Pemesanan adalah halaman yang digunakan untuk melakukan konfirmasi pemesanan. Ada dua tabel pada halaman konfirmasi pemesanan yaitu tabel Data Pemesanan dan tabel Konfirmasi. Tabel data pemesanan berisi kolom Tgl Pesan, Tgl Batas, Tipe Pengiriman, Alamat Kirim, Status dan Detail. Tabel konfirmasi berisi form konfirmasi dimana kolom No Pemesanan, Bank Asal, Atas Nama, Nominal dan Bukti Transfer (melampirkan struk). 


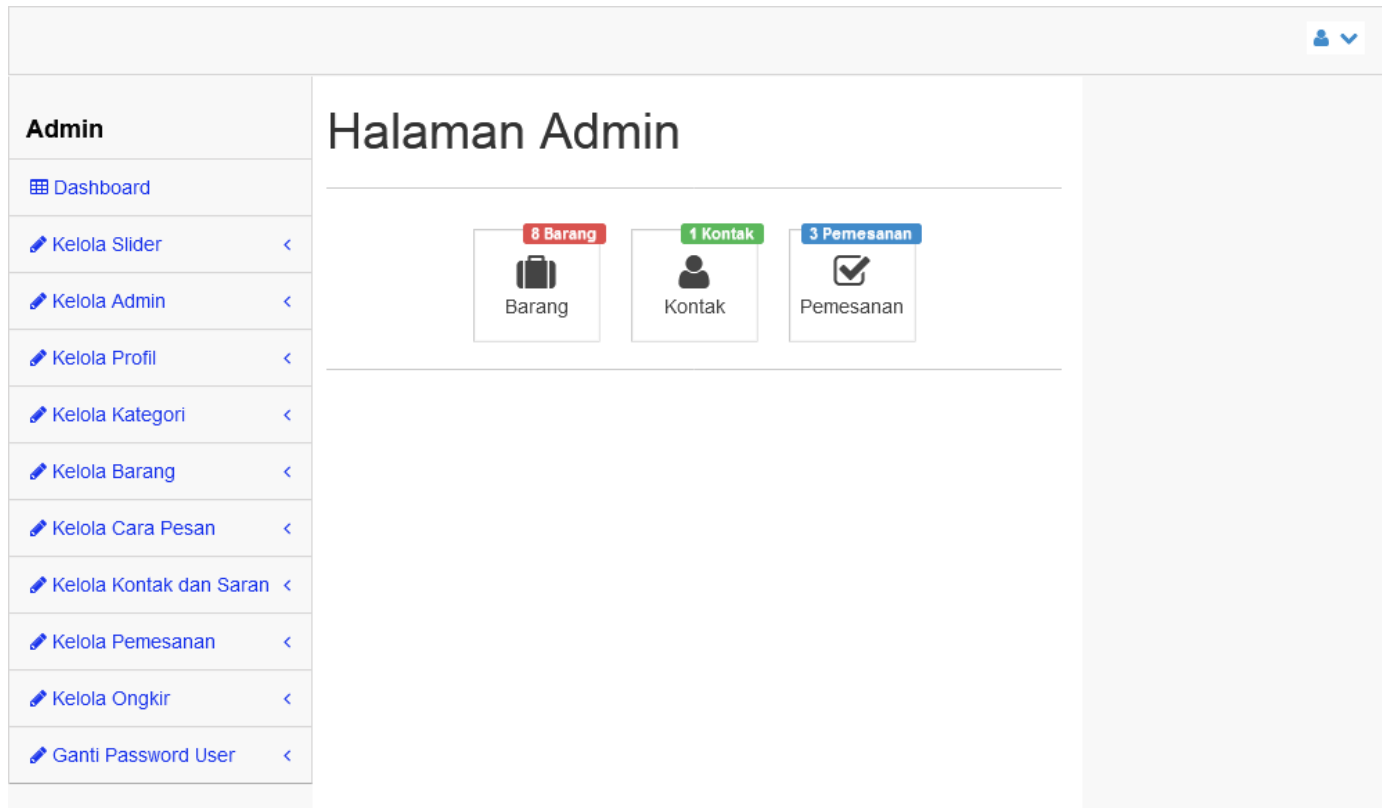

Gambar 3.4 Halaman Admin Dashboard

Halaman Admin Dashboard adalah halaman awal masuk untuk admin terdapat notifikasi produk, kontak dan pesanan. Admin mengisi dan mengelola data slider, admin, profil, kategori, barang, cara pesan, kontak dan saran, pesanan, ongkir dan ganti password user.

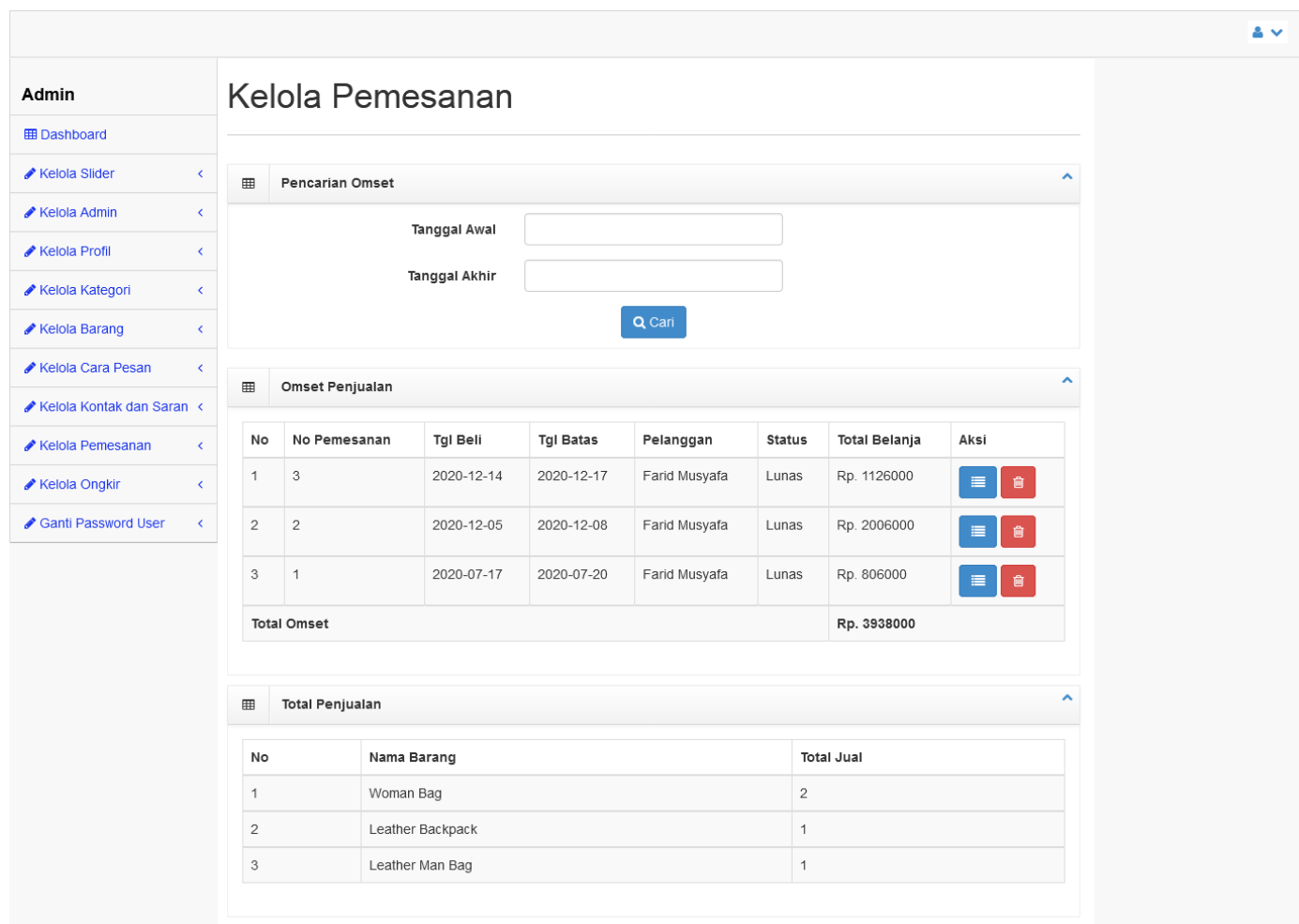

Gambar 3.5 Halaman Kelola Pemesanan

Halaman Kelola Pesanan adalah halaman yang digunakan admin untuk mengecek detail pesanan dan melakukan konfirmasi pemesanan. Terdapat tiga tabel yaitu tabel Pencarian Omset, tabel Omset Penjualan dan tabel Total Jual. Tabel Pencarian Omset berisi form yang terdiri dari kolom Tanggal Awal dan Tanggal Akhir. Tabel Omset Penjualan teridi dari kolom No, No Pemesanan, Tgl Beli, Tgl Batas, Pelanggan, Status, Total Belanja dan Aksi. Tabel Total Penjualan terdiri dari kolom No, Nama Barang dan Total Jual. 


\section{KESIMPULAN}

Sistem informasi penjualan pada CV. Purnama berbasis web dirancang bukan untuk menggantikan sistem yang telah ada akan tetapi merupakan penambahan komponen sistem yaitu mengonlinekan-kan aktivitas penjualan yang sebelumnya hanya bersifat offline. Berdasarkan hasil dari analisis dan perancangan sistem yang dibangun, maka dapat diambil kesimpulan sebagai berikut :

1. Dengan Dengan adanya website ini maka CV. Purnama dapat memperluas cakupan pemasaran dan memudahkan konsumen dalam memperoleh informasi produk tanpa harus mengunjungi langsung CV. Purnama.

2. Dengan tersedianya sistem penjualan (e-commerce) maka CV. Purnama dapat menyederhanakan proses transaksi konvensional untuk memodernisasi transaksi online. Pelanggan di luar Kota Sidoarjo tetap bisa menyelesaikan transaksi tanpa harus datang langsung ke CV. Purnama.

3. Dengan adanya website ini memungkinkan admin untuk menyederhanakan pembuatan laporan penjualan yang dibuat secara manual sebelumnya.

\section{UCAPAN TERIMA KASIH}

Keberhasilan penelitian ini tidak lepas dari bimbingan, bantuan, dorongan semangat dari berbagai pihak. Oleh karena itu dengan segala kerendahan hati penulis ingin mengucapkan terima kasih kepada seluruh pihak yang berperan dalam penelitian ini terutama CV. Purnama sebagai lokasi studi kasus dalam penelitian ini, dan Labolatorium Informatika Universitas Muhammadiyah Sidoarjo sebagai pendukung dalam penelitian ini.

\section{REFERENSI}

[1] Iriadi, N., \& Indrasari, A. U. (2017). Sistem Informasi Penjualan Berbasis Web Pada CV. Bambu Jaya Jakarta. Journal Speed - Sentra Penelitian Engineering dan Edukasi, Volume 9 No 3, 34-39.

[2] Ferdika, M., \& Kuswara, H. (2017). Sistem Informasi Penjualan Berbasis Web Pada PT Era Makmur Cahaya Damai Bekasi. Information System For Educators And Professionals, 175-188.

[3] Imaniawan, F. F., \& Elsa, U. M. (2017). Sistem Informasi Penjualan Sepatu Berbasis Web Pada Vegas Hyper Purwokerto. Indonesian Journal On Software Engineering, Volume 3 No 2, 82.

[4] Barkah, D., \& Wasiyanti, S. (2018). Sistem Informasi Penjualan Baju Berbasis Web Pada Project Distro Depok. p-ISSN: 141-8637 e-ISSN: 2550-1178, Volume XVI No., 125.

[5] Arikunto, S. (2013). Prosedur Penelitian Suatu Pendekatan Praktik. Jakarta: Rineka Cipta.

[6] Sugiyono. (2012). Memahami Penelitian Kualitatif. Bandung: Alfabeta.

[7] Khatibah. (2011). Penelitian Kepustakaan. Iqra': Jurnal Perpustakaan dan Informasi, 05(01), 36-39.

[8] Putri, S. H., \& Mulyono, H. (2017). Aanalisis dan Perancangan Sistem Informasi Penjualan Berbasis Web Pada UD. Cakra Motor. Jurnal Manajemen Sistem Informasi, Vol. 2, No. 4, 823.

[9] Sukamto, \& Shalahuddin. (2013). Rekayasa Perangkat Lunak. Bandung: Informasi Bandung.

[10] Prayitno, A., \& Safitri, Y. (2015). Pemanfaatan sistem informasi perpustakaan digital berbasis website untuk para penulis. Indonesian Journal on Software Engineering, 1(1), 2015. 